\title{
Predicting ship machinery system condition through analytical reliability tools and artificial neural networks
}

\author{
I. Lazakis ${ }^{1}$, Y. Raptodimos ${ }^{1}$, T. Varelas ${ }^{2}$ \\ ${ }^{1}$ Department of Naval Architecture, Ocean and Marine Engineering, University of Strathclyde, Glasgow G4 OLZ, \\ United Kingdom \\ ${ }^{2}$ Danaos Shipping Company Ltd., Piraeus 185 45, Greece
}

Inadequate ship machinery maintenance can increase equipment failure posing a threat to the environment, affecting performance, having a great impact in terms of business losses by reducing ship availability, increasing downtime and moreover increasing the potential of major accidents occurring and endangering lives on-board. This paper aims to provide a systematic approach for identifying critical ship machinery systems/components and to analyse their physical parameters. Critical ship main engine systems/components are used as input in a dynamic time series neural network, in order to monitor and predict future values of physical parameters related to ship critical systems. The critical main engine systems/components and their relevant parameters to be monitored are identified though the combination of Fault Tree Analysis (FTA) and Failure Mode and Effects Analysis (FMEA). A case study of a Panamax size container ship is presented in which Artificial Neural Networks (ANN) are used to predict the upcoming values of all main engine cylinders exhaust gas temperatures. The forecasted results were validated through comparison with actual observations recorded on board the ship. The proposed hybrid methodology successfully presents a systematic approach for initially identifying critical systems/components through reliability modelling and tools and subsequently monitoring their physical parameters through neural networks.

\section{Introduction}

Maintenance tasks affect the reliability and availability levels of the shipping industry and are important factors in the lifecycle of a ship that can minimize down-time and reduce operating costs as is accounts for $20 \%-30 \%$ of a ship's operational expenses (Stopford, 2009). Also, due to the impact of shipping on the environment and the importance of the safe operation of ships; ship owners and operators pursue to adopt a maintenance plan and procedures that will reduce costs and promote the lifecycle integrity of the ship. Although the maritime industry is responsible for the massive transportation of goods worldwide, it is only recently that new approaches investigating the enhancement of ship's reliability, availability and profitability have been considered according to Lazakis and Olcer (2015). Though the industry is still predominantly reliant on a time-based, prescriptive approach to maintenance, there are a number of factors challenging the long-held norm. The increasing complexity of shipboard systems, heightened expectation and competitive needs as to ship and plant availability and efficiency and the influence of the data revolution on vessel operations, favour a properly structured Condition Based Maintenance (CBM) regime. This may not replace all planned maintenance, but it can possibly reduce downtime, inspection and unnecessary servicing work. The advocates of change argue that a move from scheduled, rule-based maintenance to a data- 
driven, risk-based approach can lead to more accurate and timely maintenance, resulting in lower costs, greater availability of ship systems and increased safety (Tinsley, 2016) .

In this respect, according to British Standard (2012), CBM is defined as the maintenance policy carried out in response to a significant deterioration in a machine as indicated by a change in a monitored parameter of the machine condition. The heart of CBM is condition monitoring which aims in collecting data regarding equipment conditions. Condition monitoring technologies are applied through various tools by recording and evaluating different measureable parameters. Data can include vibration, acoustic, temperature, current signal, oil and lubricant measurements (Pascual, 2015). Compared to other industrial applications, in the shipping industry data pooling is not always possible as similar equipment in different conditions may have different failure patterns. Another issue is the constant appearance of new equipment, which makes historical records obsolete. Moreover, data is not collected in a standardised way so that it can lead to more informed and successful decision making (Dekker, 1996). Technological advances and high cost of ownership have resulted in considerable interest in advanced maintenance techniques. Raza and Liyanage (2009) stated that there has been an increasing demand for testing and implementing intelligent techniques as a subsidiary to existing condition monitoring programs and that ANNs have emerged as one of the most promising techniques in this regard.

The question of how much data, which data, and how often this should be collected and how has also risen; as although companies adopt CBM schemes, there seems to be an issue in processing, analysing and utilising the recorded operational data. This paper aims to identify critical systems of a ship's main engine through the combination of the FTA and FMEA tools and to further examine them through monitoring their physical parameters. The physical parameters are used as input for time series analysis and forecasting using artificial neural networks.

The present research paper is organized as follows: Section 2 presents the maintenance overview and status in the maritime industry alongside the methodologies/tools implemented in detail. In Section 3 the suggested methodology is demonstrated and explained. Section 4 presents the case study application through which the methodology is applied alongside the obtained results. Finally, the discussion and conclusion of this research study is presented in Section 5 .

\section{Research Background/Literature}

The evolution of maintenance was based not solely on technical but rather on techno-economic considerations according to Pintelon and Parodi-Herz (2008). Furthermore, according to Arunraj and Maiti (2007), maintenance policies can be categorised into four generations as seen in Figure 1. The fourth generation is the most recent one, which focuses on condition based maintenance, condition monitoring and failure eliminations. It concentrates on reducing the proportion of equipment failures and overall levels of failure probability through various tools and strategies, based on preventive and predictive maintenance approaches. 


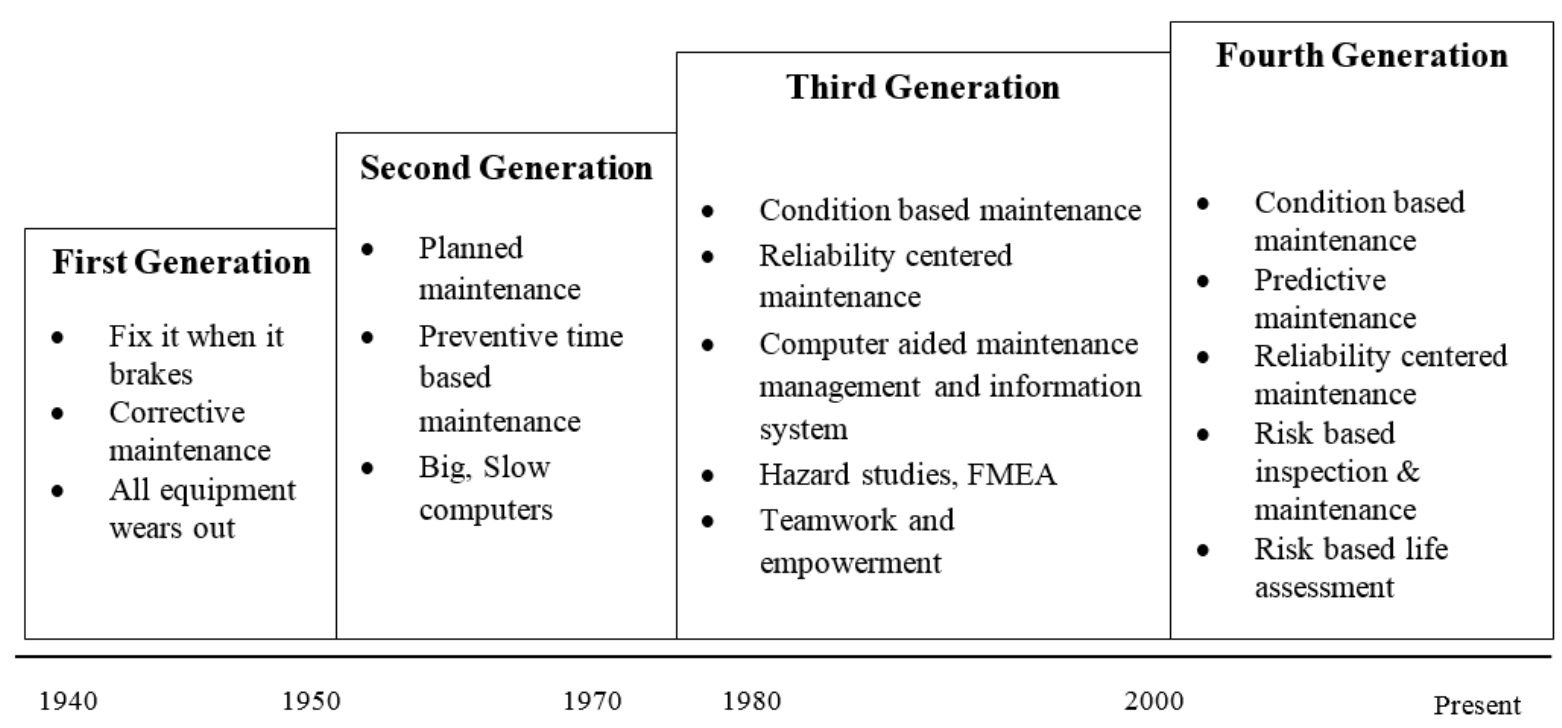

Fig. 1. Evolution of Maintenance (Adapted by Arunraj \& Maiti 2007)

Examining Figure 1 and associating it with maintenance in the shipping industry, it can be observed that maintenance was initially treated as a necessary evil and has now started to be considered an important factor in the operational management and lifecycle of ships. Lloyd's Register (2013) published a report regarding machinery planned maintenance and condition monitoring which was revised in order to add machinery condition based maintenance procedures and describe how a machinery planned maintenance scheme can be accepted as an integral part of the continuous survey machinery cycle. Class NK introduced the concept of PrimeShip-Total Ship Care (2013) which has been designed to prevent pollution of the marine environment and ensure safety of ships at every stage of a ships life including maintenance. The product contributes to improved reliability and increased efficiency of hull structure analysis, machinery shaft alignment and torsional vibrations and maintenance management amongst others. DNV-GL also published a paper in 2014 regarding condition monitoring in the shipping industry reviewing existing condition monitoring technologies and methods for implementing such technologies (Knutsen et al., 2014). The American Bureau of Shipping (ABS) introduced the NS5 Entreprise software (2015b) aiming to handle the primary functions of operational management-maintenance, supply chain, workforce, environmental and safety. Classification Societies encourage condition monitoring techniques on board ships, offer guidelines but do not oblige ship operators or owners to implement such techniques in their operation and maintenance. Furthermore, Lazakis and Olcer (2015) introduced a Reliability and Criticality Based Maintenance (RCBM) strategy by utilizing a fuzzy multiple attributive group decision-making technique, which is further enhanced with the employment of Analytical Hierarchy Process (AHP). The outcome of this study indicated that preventive maintenance is still the preferred maintenance approach by ship operators, closely followed by predictive maintenance; hence, avoiding the ship corrective maintenance framework and increasing overall ship reliability and availability. However, most shipping companies still follow the so called Planned Maintenance System (PMS) based on ISM code (IMO, 1993) which is centred on the preventive maintenance scheme, in which machinery items are maintained based on operating hours or calendar intervals. A brief discussion of the methods 
applied in this paper is presented below, while the specifics of how they were applied to the case study are given in detail in Section 3.

\subsection{Failure Modes and Effects Analysis (FMEA)}

FMEA provides a systematic method for organizing the study of a particular system or process in terms of failure analysis. The aim of FMEA is to review the system in order to provide details on how to identify failures and their causes as well as determine the end results of the failures occurring. Thus, FMEA is a formalized method to consider all components, their functions, failure modes and system failures (Isermann, 2006). It involves reviewing as many components, assemblies and subsystems as possible to identify possible failures modes and causes and effects of such failures. FMEA can be applied in a bottom-up approach which assists in mapping the overall failure potential of the system. This technique is most suited for the risk assessment of mechanical and electrical systems and the approach can be either quantitative or qualitative. According to Ben-Daya and Knezevic (2009) FMEA performs three functions. These are initially the identification and recognition of potential failures including their causes and effects, the evaluation and prioritization of identified failure modes and the identification and suggestion of actions to either eliminate or reduce the chance of the potential failures from occurring.

The American Bureau of Shipping has released guidance notes (ABS, 2015a) related to FMEA requiring the development and submission of FMEAs as part of Classification requirements for certain systems such as Dynamic Positioning systems, drilling systems, dual fuel diesel engines etc. The International Association of Classification Societies (IACS) (2014) published recommendations for the FMEA process for diesel engines and reporting the FMEA process. To contribute and improve the ongoing efforts of Classification Societies and operators, Cicek and Celik (2013) examined the application of FMEA in order to prevent and reduce the occurrence of crankcase explosion failure in order to improve machinery system reliability and enhance operational safety on board ships.

FMEA can favourably be combined with FTA because it yields the possible system failures, which are inputs of FTA. Also, an FTA may use the basic failure mode FMEA records or an effect summary as one of its inputs (basic events). Therefore FMEA and FTA complement each other (Isermann, 2006). Specifically, Souza and Alvares (2008) applied FMEA in conjunction with Fault Tree Analysis (FTA) as a risk assessment tool for the application of Reliability Centred Maintenance. The methodology was used to study and analyse the failure mode of a hydraulic Kaplan turbine and showed that the two tools can complement each other for the execution of an effective predictive maintenance plan on the basis that the FMEA analysis provided the information required for the FTA basic event. Hidalgo et al. (2011) carried out the failure analysis of steering systems for LNG carriers. FTA was developed in order to identify the most critical components for the steering gear system and then the application of FMEA was conducted for each critical component in order to identify the failure modes and provide appropriate maintenance policies based on reliability centred maintenance philosophy. Furthermore, Gao and Kang (2016) applied the FMEA method for the reliability 
analysis of the main failure events and their interrelations of the offloading systems of an FPSO. The main failure events were then demonstrated using a Fault Tree.

\subsection{Fault Tree Analysis (FTA)}

FTA is a systematic technique used for acquiring information on a system and finding out how the system or its components could contribute to a failure and can assist decision-making process developed by safety and maintenance engineers who plan and organize maintenance and monitoring activities (Manzini et al., 2009). It is a failure-oriented, deductive, top-down approach which considers an undesirable event associated with the system as the top event; the various possible combinations of fault events leading to the top event are represented with logic gates. Therefore, the fault tree is a qualitative model which provides useful information on the various cases of undesired top events (Verma et al., 2010). The graphical representation is done through Fault Tree diagrams which are a graphical design technique following a top-down approach. It uses a graphic model of the pathways within a system that can lead to a projected, undesirable event or failure. The pathways interconnect contributory events and conditions, using standard logic symbols and the basic constructs in a fault tree diagram are gates and events. The fault tree analysis module is based on sets of rules and logic symbols from probability theory and Boolean algebra. Gates represent logic operators that link the various branches of the fault tree together, can be either static or dynamic and determine whether the top event can occur or not. The gates show the relationship of events needed for the occurrence of a higher event and serve to permit or inhibit the fault logic up the tree. Basic events can be defined as the lower level events in each fault tree branch. A static gate indicates that the order of the inputs of a gate do not matter, therefore are not sequence-dependent as in dynamic gates. On the other hand, in dynamic gates, the order of the occurrence of input events is vital for determining the output. If dynamic gates are used, then the fault tree becomes a dynamic fault tree. A thorough description of advanced fault tree symbols can be found in NASA (2002) and NUREG-0492 (1981).

A FTA is normally carried out by defining the FTA scope and identifying the top event, followed by defining the levels of the FT and connected the levels by using gates (Rausand and Arnljot, 2004). The FTA can be conducted in a qualitative or quantitative manner, depending on the type of data available. If no data is available, a fault tree can be analysed qualitatively by using minimal cut sets. Finding minimum cut-sets provides insight into weak points of complex systems. Qualitative analysis is used to identify what combinations of events cause the top event to occur. Ultimately, failure rates are derived from well-substantiated historical data, including MTBF of components, units and subsystems (Pascual, 2015). FTA uses failure rates, mean time between failures and minimal cut sets to evaluate the reliability and availability of the system.

Specifically, Lazakis et al. (2010) presented a predictive maintenance strategy utilizing Failure Modes, Effects \& Criticality Analysis (FMECA) and FTA by considering the existing ship maintenance regime as an overall strategy including technological advances and decision support system by combining existing ship operational and maintenance tasks with the FTA and FMECA tool. An innovative ship maintenance strategy is also presented by Turan et al. 
(2011) based on criticality and reliability assessment while utilising the FTA tool with timedependent dynamic gates in order to accurately present the interrelation of the components for a diving support vessel. However, the above papers utilise the Fault tree capabilities by using quantitative methods of analysis and data such as FR, MTBF. Laskowski (2015) applied the FTA as a tool for modelling the reliability structure of a marine main engine by conducting qualitative means of analysis using the minimal cut sets method. Moreover, Guan et al. (2016) presented a Fault Tree model considering fires and explosion in a dual fuel engine room as the top event. The primary factors that affect these kinds of accidents are determined through minimum cut sets and based on the results; suggested measures are proposed to improve safety and reliability. Ananthraraman et al. (2014) created a Fault Tree for a two stroke main engine lube oil system in order to examine the reliability of the overall system and identify critical components and demonstrated that with the use of additional components in the system, component reliability could be increased which contributed to the overall reliability of the main engine lubrication system.

\subsection{Artificial Neural Network (ANN)}

A neural network can be defined according to Haykin (1998) as a massively parallel distributed processor made up of simple processing units that has a natural propensity for storing experiential knowledge and making it available for use. It resembles the brain within two respects; knowledge is acquired by the network from its environment through a learning process and interneuron connection strengths, known as synaptic weights, are used to store the acquired knowledge. An ANN consists of interconnection of neurons assembled in layers. Each layer has a number of simple, neuron processing elements called nodes or neurons that interact with each other by using numerically weighted connections. It consists of $n$ layers of neurons of which two are input and output layers, respectively. The former is the first and the only layer which receives and transmits external signals while the latter is the last and the one that sends out the results of the computations. The $\mathrm{n}-2$ inner ones are called hidden layers which extract, in relays, relevant features or patterns from received signals. Those features considered important are then directed to the output layer. Sophisticated neural networks may have several hidden layers, feedback loops, and time-delay elements, which are designed to make the network as effective as possible in discriminating relevant features or patterns. Figure 2 displays a simple structure of a typical ANN with one input, hidden and output layer respectively.

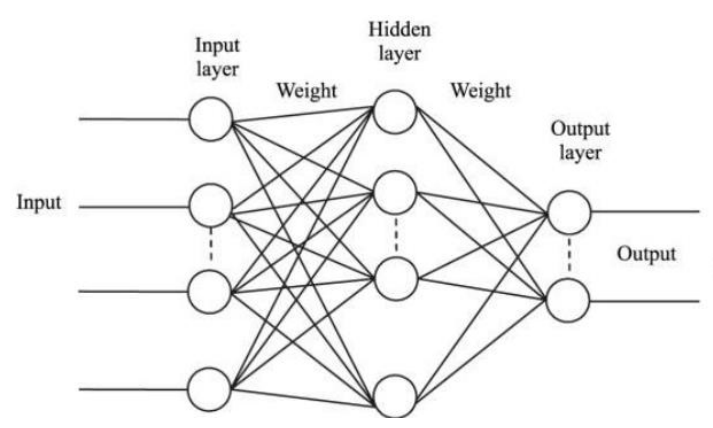

Fig. 2. Artificial Neural Network Structure (Zhang et al., 1998) 
According to Nasr et al. (2012) ANNs provide an effective analysing and diagnosing tool to understand and simulate the nonlinear behaviour of complex systems and can be used as a valuable performance assessment tool for operators and decision makers. ANN are trained to learn from past examples and capture subtle functional relationships among data provided even if the underlying relationships are hard to describe or unknown. They can readily address modelling problems that are analytically difficult and for which conventional approaches are not practical, including complex physical processes having nonlinear, high-order, and timevarying dynamics and for which analytic models might not yet exist (Peng et al., 2010). Zhang et al. (2001) showed that neural networks are valuable tools for modelling and forecasting nonlinear time series while traditional linear methods are not as competent for this task. The lack of systematic approaches to neural network model building is probably the primary cause of inconsistencies in reported findings.

Although artificial neural networks have recently gained importance in time series applications (Aizenberg et al., 2016, Szoplik, 2015, Liu et al., 2015, Laboissiere et al., 2015), some methodological shortcomings still continue to exist, such as proper network selection, architecture and learning algorithms. Aizenberg et al. (2016) performed time series analysis using multilayer neural network for forecasting oil production in the Gulf of Mexico. They concluded that the choice of embedding dimensions from time series data is a challenging and ongoing task requiring additional research effort. Moreover, Noor et al. (2016) applied ANN modelling on a marine diesel engine in order to predict its performance in terms of output torque, brake power, brake specific fuel consumption and exhaust gas temperature using as input data various engine speeds and loads. The network was based on a standard backpropagation Levenberg-Marquardt training algorithm and results were compared with those of a mathematical model. Results showed that the prediction error of the ANN model was lower than the mathematical model. Raptodimos and Lazakis (2016) created a dynamic autoregressive neural network for predicting the upcoming 5 hourly exhaust gas temperatures for a cylinder of a marine diesel engine. The prediction results were compared with actual data and showed that the network was accurate in predicting these values.

In terms of combining reliability tools with ANN, Rulin and Lowndes (2010) proposed the use of a coupled FTA and ANN model in order to improve the prediction of the potential risk of coal and gas outburst events during mining. Parameters identified from the FTA were subsequently used as input variables to a predictive ANN model in order to predict the potential risk occurrence of coal and gas outburst events. Their findings presented that the FTA was successful in determining the critical events of the system and the ANN model although consistent, could improve in accuracy by increasing the training parameters of the back propagation algorithm. Furthermore, Guoping et al. (2013) combined a Fault Tree for an excavator hydraulic system with ANN for fault diagnosis. Their results demonstrated that the network was feasible and effective for fault diagnosis and further research should be conducted due to the optimistic results of the methodology. Based on the literature presented, a novel methodology is hence required to address the above identified gaps and shortcomings. 


\section{Methodology}

The overall methodology applied in this paper is illustrated in Figure 3. Initially, a generic model is developed utilising the FMEA and FTA modelling tools in order to identify the most critical subsystems and components of the main system under investigation. Subsequently, the ANN model is developed in order to transform the generic model into a more specific one, by using physical parameters of the most critical items of the FTA as input in the neural networks for time series analysis and forecasting.

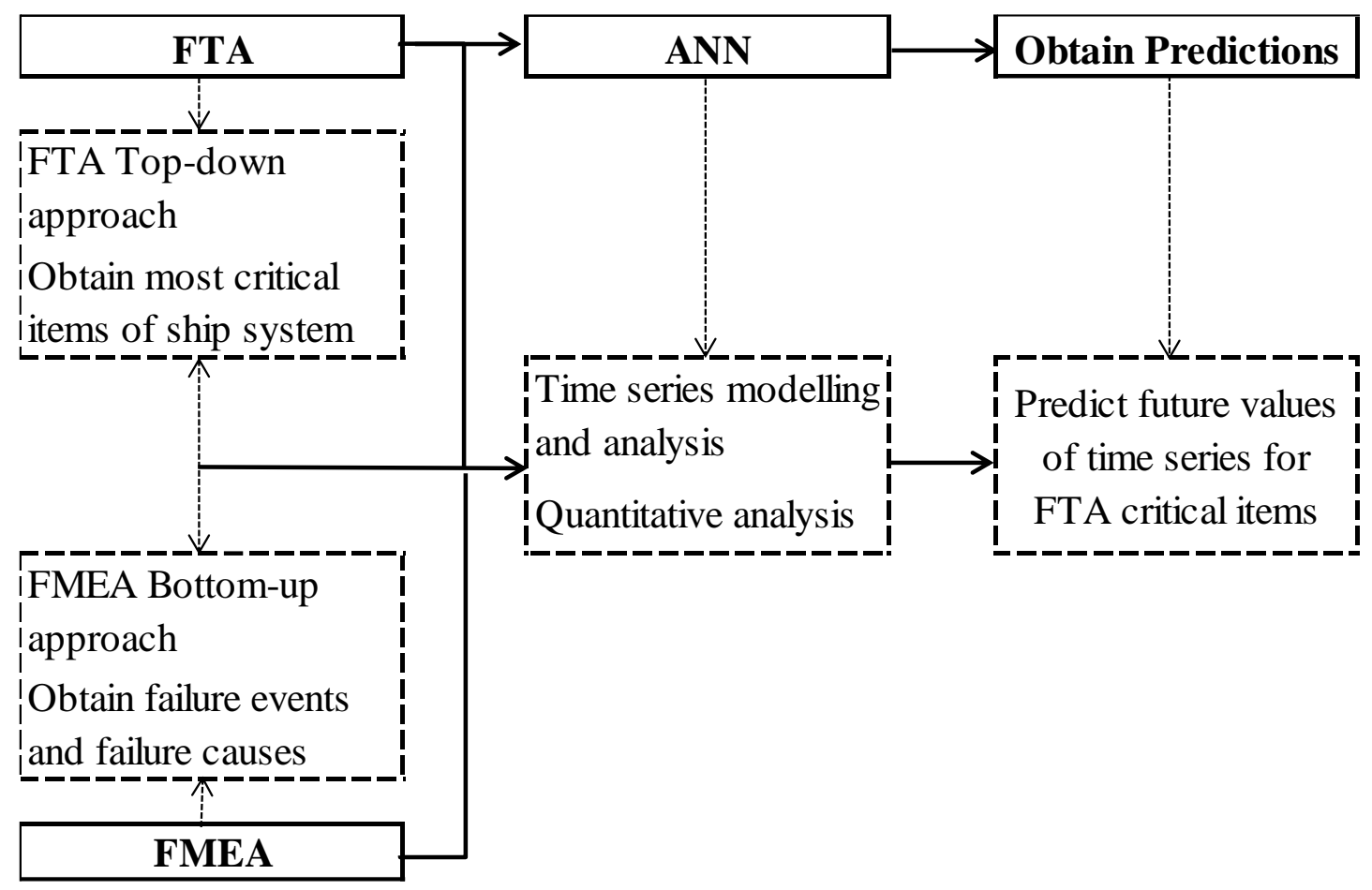

Fig. 3. Overall hybrid Predictive Methodology

\subsection{FTA \& FMEA Model}

System definition is a very important part of FTA. The basis of the system definition is the Fault Tree diagram which defines all interconnections and components of the system. Also, reliability parameters should be identified and the system definition must provide all related assumptions regarding the system and the conditions that indicate that the components of the system have failed. The top gate should also be clearly defined as if a top event is not concisely defined then the Fault Tree can possibly become too large and complex, resulting in an unfocused system analysis. Logical relationship between top events and basic events of the Fault Tree can also be verified based on FMEA analysis and results. The two tools can complement each other on the basis that the FMEA provides information required for the FTA basic event. Thus, both can provide a complementary way of identifying errors and tracking their possible influences. The connection and combination of these two tools for this methodology is graphically demonstrated in Figure 4. 


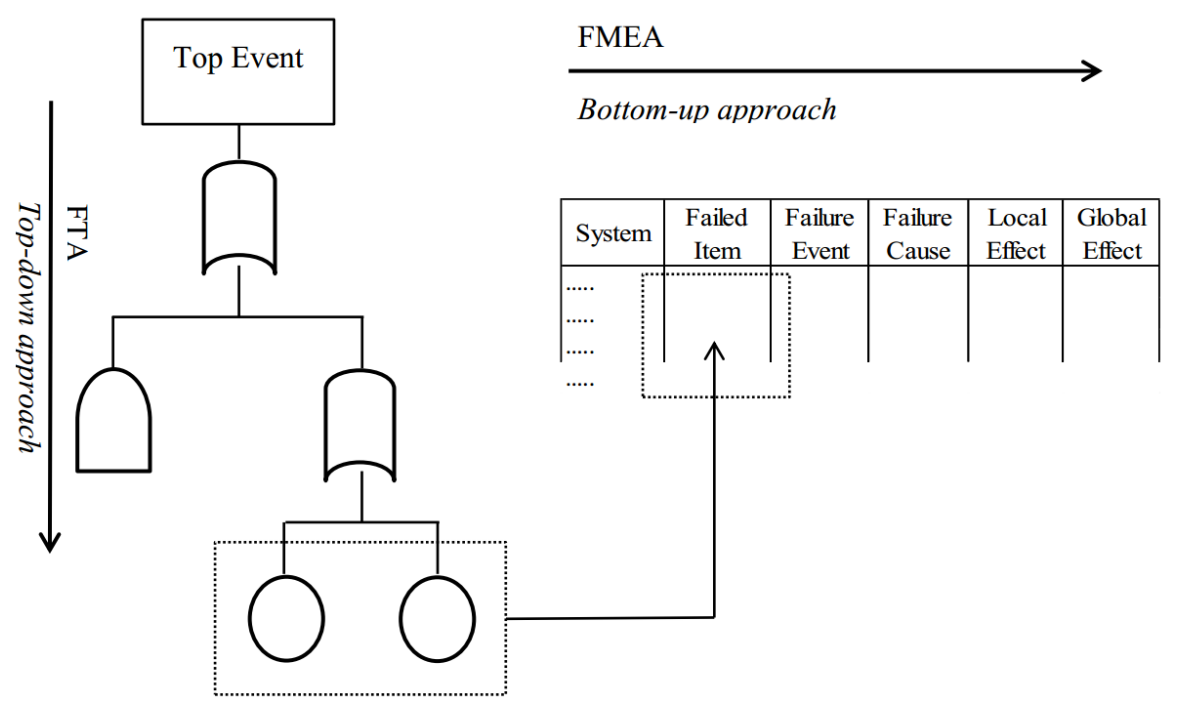

Fig. 4. Combination of FTA-FMEA tools

The FTA is a deductive, top-down approach in which the main system (top event) is divided into its subsystems and they are consequently analysed to their components, which is the last level of the fault tree (basic events). As shown in Figure 4, the basic events of the Fault Tree are used as input in the FMEA. The FMEA is an inductive, bottom-up approach in which the components of the Fault Tree (basic events) are the failed items of the FMEA worksheet. The system tab in the worksheet is considered the subsystems of the Fault Tree. For each failed item, all possible failure events and failure causes are considered alongside their effect in a local and global scale for the subsystems and top event respectively. Therefore, the combination of the FTA and FMEA provides significant information regarding critical components, their possible failures and causes and their effects not only in component, but also in subsystem level, which affects the overall performance and reliability of the main system (top event). Furthermore, the referred combination also provides important information regarding which physical parameters affect the performance of components as fluctuations in these physical parameters can lead to possible failures.

The following steps are performed for the construction of a Fault Tree (NASA, 2002): definition of the FTA scope, identification of the top event, identification of the first level events, connection of the first level events with the top event by means of gates, identification of the second level events, connection of the second level events with first level by using gates, repetition of the above steps for all subsequent event levels. FTA can be performed qualitatively or quantitatively. If data is unavailable, a Fault Tree can be analysed by using the minimal cut sets method. By using qualitative analysis, the combinations of events that cause the top event to occur can be identified.

A cut set is a set of basic events, which if they all occur, will result in the top event of the fault tree occurring. A minimal cut set is a combination (intersection) of primary events sufficient for the top event. The combination is a minimal combination in that all the failures are required for the top event to occur; if one of the failures in the cut set does not occur, then the top event will not occur. To determine the minimal cut sets of a fault tree, the tree is first translated to its 
equivalent Boolean equations. These equations can be used to determine the associated minimal cut sets. The minimal cut set expression for the top event can be written in the general form according to (NASA, 2002):

$T=M_{1}+M_{2}+\ldots+M_{k}$

where $T$ is the top event and $M_{i}$ are the minimal cut sets, each of them consisting of a combination of specific component failures. The general n-component minimal cut can be expressed as:

\section{$M_{i}=X_{1} \bullet X_{2} \bullet \ldots \bullet X n$}

where $X_{1}, X_{2}, \ldots, X_{n}$ are basic component failures.

Gates are logic operators within the Fault Tree that determine how events are generated and can be either static or dynamic. A basic event represents the lowest level of a fault tree. A static gate indicates that the order of the inputs of a gate do not matter, therefore are not sequencedependent as in dynamic gates. On the other hand, in dynamic gates, the order of the occurrence of input events is vital for determining the output. If dynamic gates are used, then the fault tree becomes a dynamic fault tree. The most common static gates include the AND, OR and Voting gates while dynamic gates include the Sequence Enforcing-gate, Priority AND-gate, Sparegate and Functional Dependency-gate amongst other (Relex, 2009).

\subsection{ANN Architecture}

Once the critical components and subsystems of the top gate have been identified from the FTA and the FMEA, the neural network is constructed for time series analysis and prediction using as input physical parameters of the identified systems. The methodology followed for the time series artificial neural network is show in Figure 5.

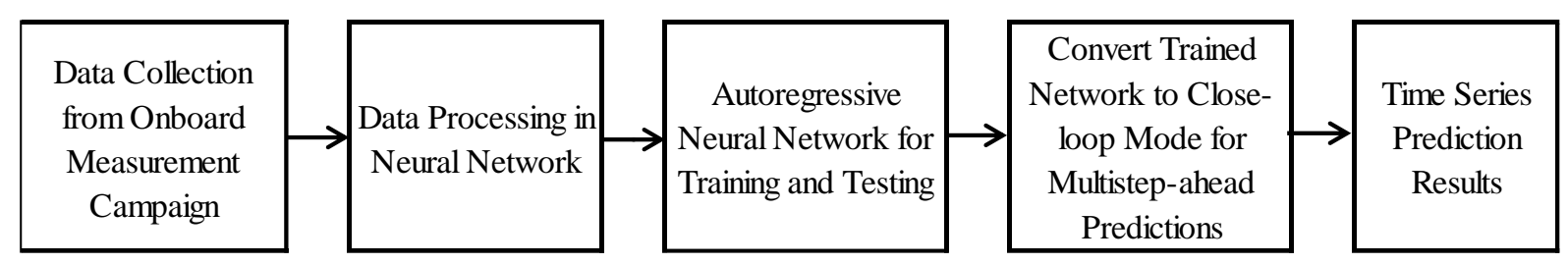

Fig. 5. Artificial Neural Network Methodology

The data consisting of physical parameter measurements is pre-processed in the ANN by mapping data to a matrix row with minimum and maximum values from -1 to 1 in order to conduct proper analysis and improve efficiency of the network training. Moreover, the neural network architecture has to be established to design a network capable of analysing and forecasting time series data. A time series is a sequential set of data points, measured typically over successive times. It is mathematically defined as a set of vectors $y(t), t=0,1,2, \ldots, d$ where $t$ represents the time elapsed (Hipel and McLeod, 1994). The variable $y(t)$ is treated as a random variable. The measurements taken during an event in a time series are arranged in proper chronological order. The future values of a time series $y(t)$ are predicted only from the 
past values of that series. This form of prediction is called nonlinear autoregressive and can be written as:

$$
y(t)=f(y(t-1), \ldots, y(t-d))
$$

Where $y(t)$ is the observation at time $t$ and $d$ is the dimension of the input vector or number of past observations used to predict the future; and $f$ is a non-linear function. The time series data is prepared by shifting time by the minimum amount to fill input states and layer states. This allows the original time series data to remain unchanged, easily customizing it for networks with different numbers of delays. Finally, data is divided into two subsets in the network for training and testing. The training set is used for computing the gradient and updating the network weights and biases and the test data is used to measure the network generalisation capabilities.

Successful ANN modelling is based upon the number of neurons, number of hidden layers, values of the weights and biases, type of the activation function, structure of the network, training styles and algorithms as well as data structure (Raza and Liyanage, 2009). However, the best structure is the one which can predict behaviour of the system as accurately as possible. A crucial step in the building of a neural network model is the determination of the number of processing elements and hidden layers in the network. Hidden nodes are used to capture the nonlinear structures in a time-series. Since no theoretical basis exists to guide the selection, in practice the number of hidden nodes is often chosen through experimentation. A nonlinear autoregressive neural network is trained in order to proceed with the prediction results. A hyperbolic tangent transfer function in the hidden layer and linear transfer function in the output layer are employed, capable of approximating any function with a finite number of discontinuities.

The neural network is a feed-forward back propagation network. During training, the network weights and biases are updated after all of the inputs and target values have been presented to the network. The network is autoregressive as the only inputs are lagged target values. The neural network is trained using the Bayesian regularization backpropagation algorithm (Kayri, 2016). The term backpropagation refers to the process by which derivatives of network error, with respect to the network weights and biases, can be computed. The performance of the network is evaluated using the Mean Square Error (MSE) average sum of square errors and Correlation Coefficient $(R)$ given by the following equations respectively (Oladokin et al., 2006):

$$
M S E=\frac{\sum_{j=0}^{P} \sum_{i=0}^{N}\left(d_{i j}-y_{i j}\right)^{2}}{N P}
$$




$$
R=\frac{\frac{\sum\left(x_{i}-x_{\text {mean }}\right)\left(d_{i}-d_{\text {mean }}\right)}{N}}{\left[\left(\frac{\sum\left(d_{i}-d_{\text {mean }}\right)^{2}}{N}\right)\left(\frac{\sum\left(x_{i}-x_{\text {mean }}\right)^{2}}{N}\right)\right]^{0.5}}
$$

where $P=$ number of output processing elements; $N=$ number of exemplars in the data set; $y_{i j}$ $=$ network output for exemplars $i$ at processing element $j$; and $d_{i j}=$ desired output for exemplars $i$ at processing element $j$.

The ANN is then trained based on the above modelling parameters. The trained ANN can then be converted to close-loop mode and the data is reformatted to simulate the network's closed loop response in order to carry out multi-step ahead predictions. The trained ANN is converted to close-loop by replacing the feedback input and creating a feedback connection from the network output to the network input, thus making the network a Recurrent Neural Network (RNN). The first two time steps of the input are used as input delay states in order to model the dynamic system. RNNs can store sequential information in the form of historical data and can be used in forecasting. In an RNN, the input nodes of the network are used as the value of the current condition $X_{t}$ and values of the previous time-series condition $\left(X_{t-1}, X_{t-2}, X_{t-3}, \ldots, X_{t-d}\right.$ and $X_{n}$ ). The value of the output $X_{t+1}$ can provide a one-step-ahead prediction of a time-series condition, which is a function of the current value $X_{t}$ and time-lagged values of the previous condition $\left(X_{t-1}, X_{t-2}, X_{t-3}, \ldots, X_{t-d}\right.$ and $\left.X_{n}\right)$. The predicted value $X_{t+1}$ of a time series, one-step ahead in the future is given by the following equation:

$X_{t+1}=F\left(X_{t}, X_{t-1}, X_{t-2}, \ldots, X_{t-l}, \ldots, X_{n}\right)$

Where, $l$ is the time lag, $X_{t+l}$ is the predicted value, $X_{t}$ is the current value or condition and $X_{t-}$ ${ }_{d}$ is the values of previous condition lagged by time $d$.

\section{Case Study \& Results}

The methodology presented in the previous sections is applied for a Panamax container ship case study. The FMEA and FTA are performed for the main engine of the ship, a MAN B\&W 8K90MC-C type engine. The physical parameters (e.g. temperature, pressure) of the most critical components identified from the Fault Tree are then used as input in ANNs in order to perform time series analysis and predict their upcoming future values. The data used in the neural networks was collected during an on board measurement campaign while the vessel was operating in the Mediterranean region. More information regarding the measurement campaign can be found in Raptodimos et al. (2016). Part of the data collected is also used as seen in Section 4.3 for validating the neural network results.

\subsection{Fault Tree \& FMEA Case Study Results}

Figure 6 defines the boundaries of the main engine FTA in order to define what is included in the analysis carried out. 


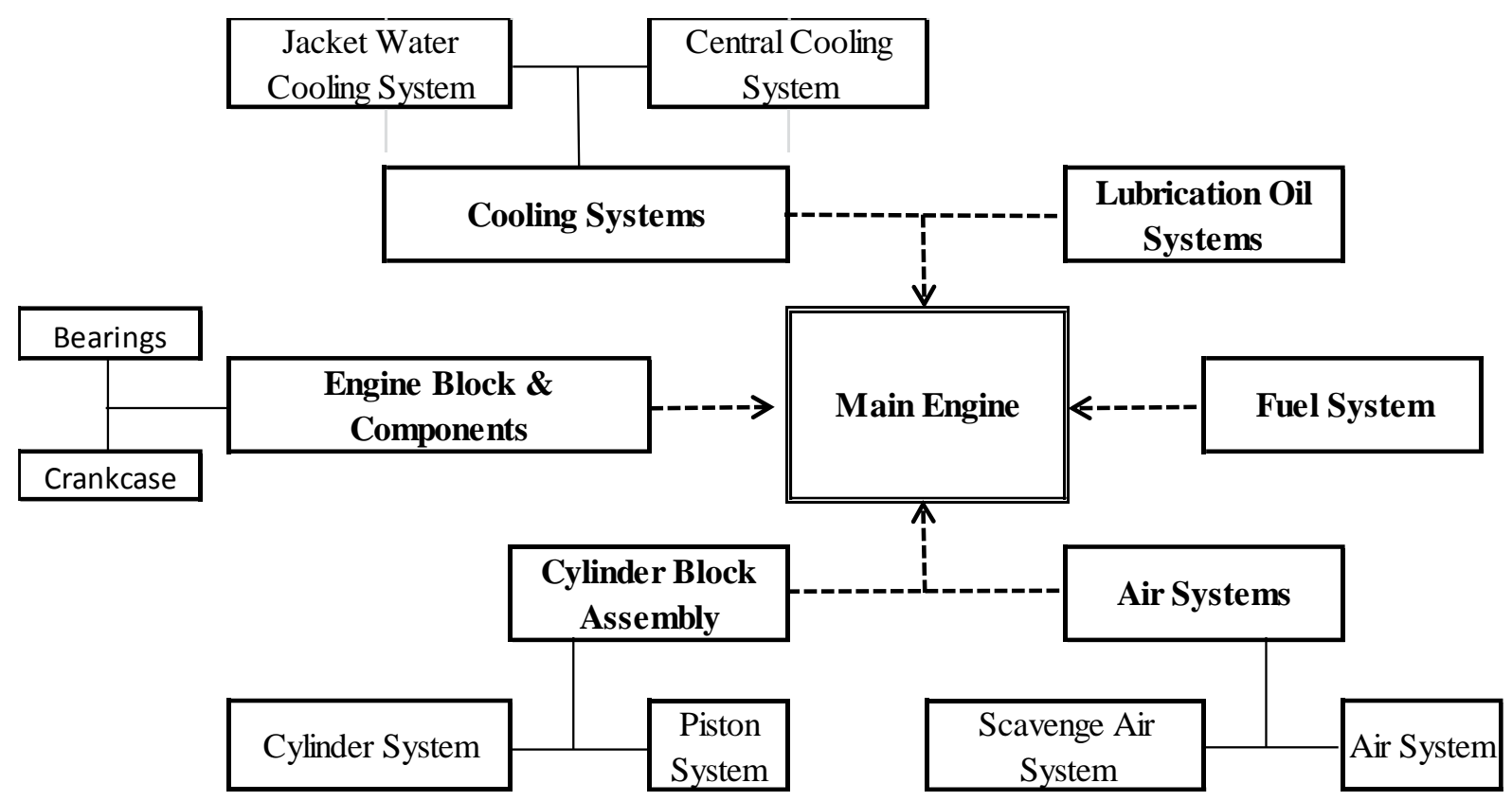

Fig. 6. Boundary conditions of main engine

As observed in Figure 6, the main engine system is divided into six sub-systems. These include the cooling, lubrication oil, fuel, air, cylinder block assembly and engine block and components subsystem. Regarding the cooling system, it is divided into the jacket water cooling and central cooling system. The jacket water cooling system consists of the jacket fresh water cooling pump and jacket water cooling and the central cooling system of the sea chest strainer, sea water pipes and central cooler. The lubrication oil system includes the lube oil filter, pump, valves and lube oil cooler. Furthermore the fuel system resembles the lube oil system with the addition of the fuel injectors. The air system is further separated into the main air system and scavenging air system. In the cylinder block assembly system, the system has been separated into the cylinder system which includes the cylinder head and liner and the piston assembly including the piston crown, rings, stuffing box and connecting rod. Finally, the engine block and components group contains components of the main engine such as the crankshaft, crankcase, camshaft and various bearings. In total, 39 basic events were modelled in the Fault Tree representing the components of the various main engine sub-systems as demonstrated in Table 1.

Table 1 Basic events used in Fault Tree

\begin{tabular}{|l|l|l|l|}
\hline Lube Oil Filter & Air Cooler, Piping & Fuel Pumps & Piston Connecting Rod \\
\hline Main Lube Oil Pump & Air Cooler & Fuel Valves & Camshaft Bearing \\
\hline Lube System Valves & Scavenge Air Port & Fuel Injector & Thrust Bearing \\
\hline Lube Oil Cooler & Scavenge Air Receiver & Main Air Compressor & Main Bearings \\
\hline JFW Cooling Pump & Scavenge Air Manifold & Air Distributor & Crankshaft \\
\hline Jacket Water Cooling & Air Receiver & Air Starting Valves & Crankcase \\
\hline Sea Chest Strainer & Cylinder Head & Air Filter & Camshaft \\
\hline Sea Water Pipes & Cylinder Liner & Auxiliary Blower & Exhaust Valves \\
\hline Central Cooler & Piston Crown & Piston Ring & Piston Rod Stuffing Box \\
\hline Fuel Piping System & Fuel Oil Filter & & \\
\hline
\end{tabular}


A four level Fault Tree for the main engine is constructed including 38 basic events and 14 gates as described in Table 1. Qualitative analysis is performed in order to obtain the minimal cut sets, which provide insight into weak points of complex systems. Figure 7, displays the overall Fault Tree for the main engine. The Fault Tree is modelled with time-dependent dynamic gates in order to represent the interrelation of the main engine system and components in an accurate and comprehensive manner. Dynamic logic gate is applied for improving veracity of fault tree.

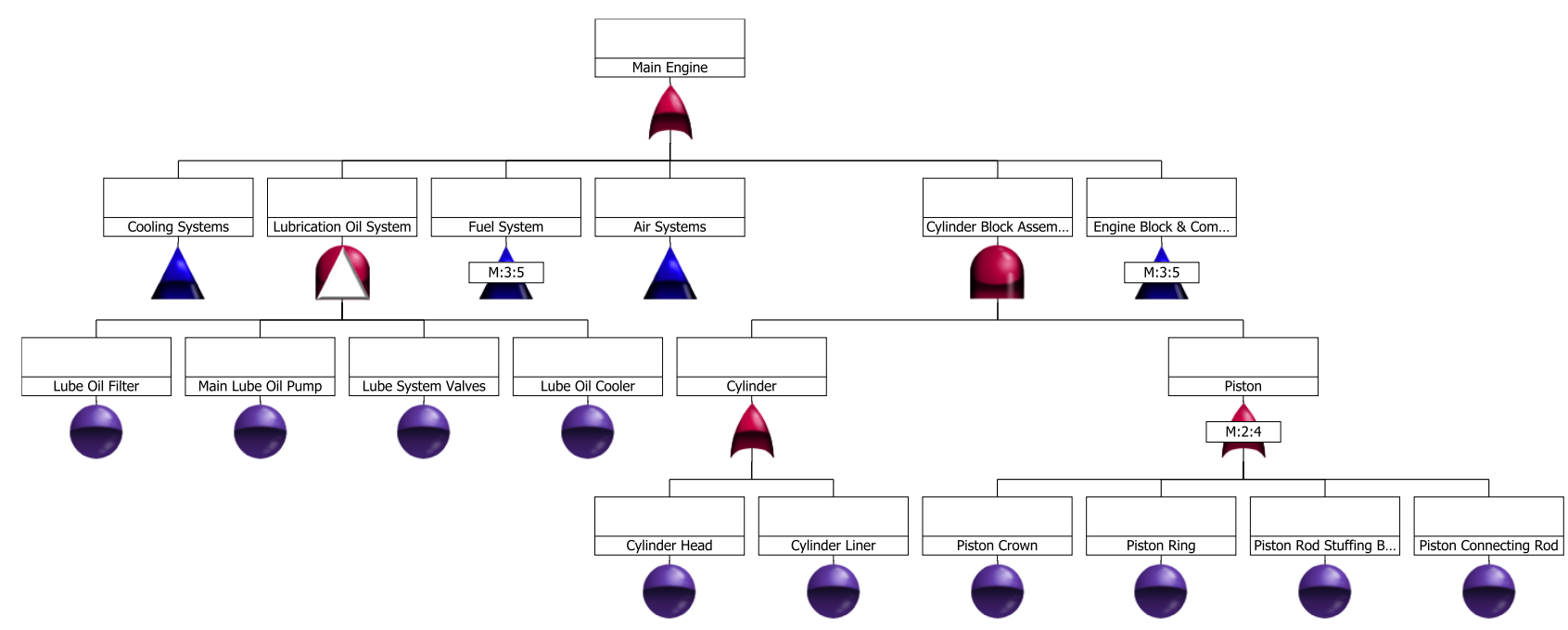

Fig. 7. Main Engine Fault Tree Diagram

The cooling system is modelled using an AND gate assuming both the jacket water cooling and central cooling system have to fail in order for the cooling system to fail. The lubrication oil system has been modelled using a Priority-AND gate, assuming that the lube oil filter failure has to occur before the pump, valves and then lube oil cooler occur. This assumption is made on the basis that a failure in the lube oil filter will have a knock back effect on the lube oil pump, valves then cooler. Thus the presented configuration allows measuring the impact of a component failure on another system component, the so-called domino effect. The fuel system has been modelled using a Voting gate of 3 out of 5 systems assuming that any three of the five components of the fuel system have to fail in order for the fuel system to fail. The air system has been modelled as an AND gate assuming that both the main air system and scavenge air system have to fail in order for the air system to fail. The cylinder block assembly gate has been modelled with an AND gate consisting of the cylinder system containing the cylinder head and liner as basic events and the piston system modelled with a Voting gate of 2 out of 4 components as seen in Figure 7. Finally, the engine block and components gate is composed of a Voting gate assuming that any three of the bearings, crankshaft, crankcase, camshaft or exhaust valves have to occur as seen in Figure 8. 


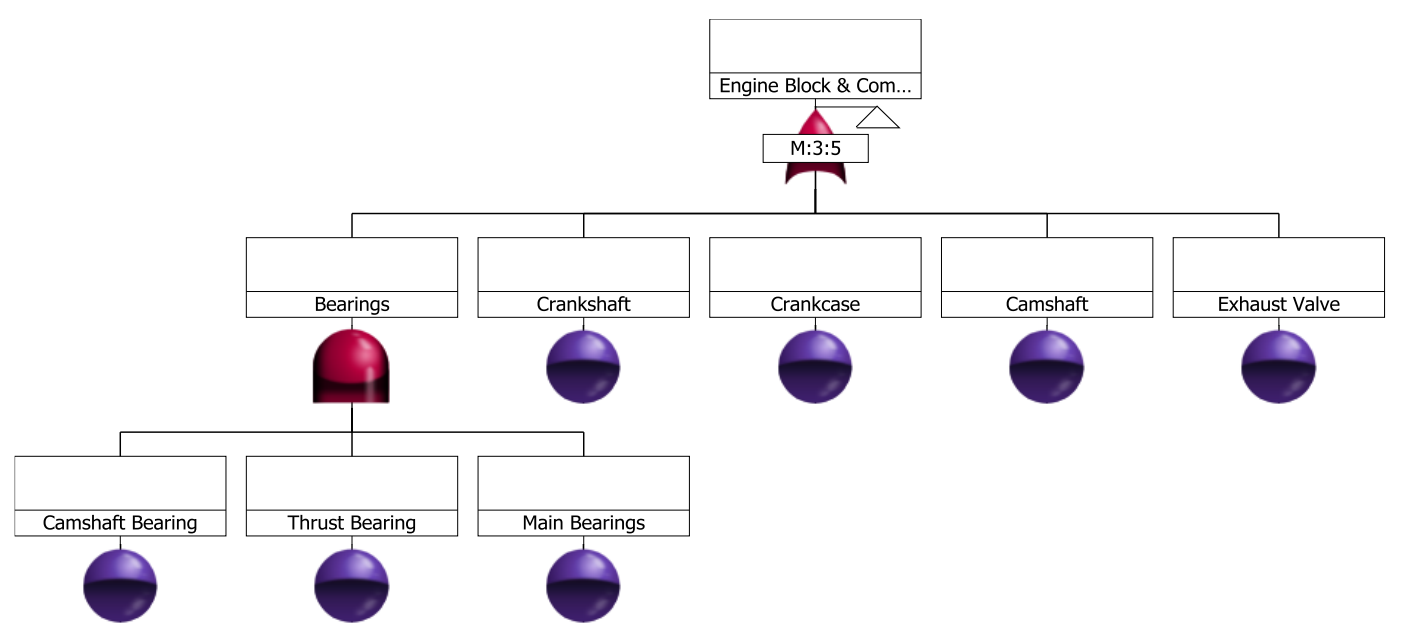

Fig. 8 Engine Block \& Components Subsystem Fault Tree Diagram

As previously discussed, cut sets are employed in order to obtain the critical components and subsystems of the top gate of the Fault Tree. Table 2 displays the top five minimal cut sets obtained from the main engine FTA. All the minimal cut sets are of third order. As observed, the first three cut sets involve systems/components that were modelled in the cylinder block assembly gate related to the cylinder and piston. The fourth cut set is related to systems in the engine block and components subsystem while the fifth is related to components of the fuel system of the main engine.

Table 2 Main Engine top five minimal cut sets

\begin{tabular}{|l|l|l|l|}
\hline 1 & Cylinder Head & Piston Crown & Piston Ring \\
\hline 2 & Cylinder Head & Piston Crown & Piston Rod Stuffing Box \\
\hline 3 & Cylinder Liner & Piston Crown & Piston Ring \\
\hline 4 & Crankcase & Crankshaft & Camshaft \\
\hline 5 & Fuel Oil Filter & Fuel Pumps & Fuel Injector \\
\hline
\end{tabular}

\subsection{Physical Parameters of Main Engine Systems}

For each system and associated component, physical parameters such as temperature and pressure are measured in order to monitor their condition. Due to availability of data during the on board measurement campaign and time constraints, these parameters were selected as a first step for the analysis of the novel methodology approach mentioned in this paper. Moreover, key parameters in performance observations of marine engines include amongst others: engine speed, barometric pressure, compression pressure, fuel pump index, exhaust gas temperatures and pressures, scavenge air temperature and pressure, air and cooling water temperatures prior and after scavenge air cooler.

The first three minimal cut sets of the FTA related to the cylinders and pistons of the main engine and by combining information retained from the FMEA worksheet, the physical parameters related to these systems and components can be identified. Table 3 displays a fraction of the FMEA for the marine cylinder block assembly system. The FMEA for the case 
study was set up by using the components of the Fault Tree as input in the Failed Item column of the FMEA spreadsheet. Afterwards, for each failed item, a list of possible failure events and failure causes is analysed alongside their local effect on the system and their global effect of the Fault Tree top gate which is the main engine. Information collected for the formation of the FMEA is based on Cicek and Celik (2013), Turan et al. (2011), Mokashi et al. (2002), Emovon (2016), INCASS EU project deliverables (INCASS, 2014b, INCASS, 2014a) and experts opinion. Information was collected from three Class societies, two ship operators and two consultancy companies. Specifically, experts included IACS Classification Societies surveyors and researchers with many years of onsite experience. Moreover, experts from ship operators and marine consultancy companies included technical managers, superintended engineers, and Chief engineers sailing onboard the mentioned vessel.

Table 3 FMEA Sample for FTA Critical Components

\begin{tabular}{|c|c|c|c|c|c|}
\hline System & Failed Item & Failure Event & Failure Cause & Local Effect & Global Effect \\
\hline \multirow{3}{*}{ Cylinder } & Cylinder Head & Cracked & Overheating, fatigue & Compession loss, cylinder damage, engine misfire & Possible engine stop \\
\hline & Cylinder Head & Overheating & Cracks, faulty exhaust values & Hightemperature alarm, smoke, cylinder damage & Possible engine stop, engine damage \\
\hline & Cylinder Limer & Wear & Fatigue, lubrication oil quality & Compession loss, increased lubrication consumption & Engine performance reduction \\
\hline \multirow{2}{*}{ Piston } & Piston Ring & Scuffing & Insufficient lubrication & Scuffing mark on liner surface, oil smoke from exhaust & Engine performance reduction \\
\hline & Piston Rod Stuffing BC & Malunction & Faulty oil scraper rings & Combustion gas in crankcase & Engine stop, possibility of explosion \\
\hline
\end{tabular}

The FMEA indicated that for a possible failure event of the cylinder head overheating or being cracked, failure causes could be faulty exhaust valves and also the effects would be high temperature alarms, compression loss and cylinder damage. In the case of the cylinder liner wear or piston ring scuffing, insufficient lubrication could be a possible failure cause. Moreover, as observed from the possible failure events and causes from the FMEA for the identified systems from the FTA; and by examining the local and global effects, the possible physical parameters that can be monitored and examined are the main engine lubrication inlet pressure and temperature, piston cooling oil pressure and cylinder exhaust gas temperatures amongst others. For the purpose of this paper, the exhaust gas temperatures for the main engine cylinders are used as input for the ANN as presented in the following section due to availability of data collected in the on board measurements campaign.

\subsection{Artificial Neural Network Case Study Results}

The neural network uses a univariate time series data set. The data collected on board the container ship case study represents 30 continuous per hour recordings of the exhaust gas temperatures for every one of the eight cylinder engine. The ANN constructed consists of one hidden layer with 8 hidden nodes as illustrated in Figure 9. A set of eight parallel neural networks with the above configuration were created in order to forecast the next 10 hourly values of each cylinder exhaust gas temperature by using in each network the 30 hourly temperature readings corresponding to each individual cylinder. 


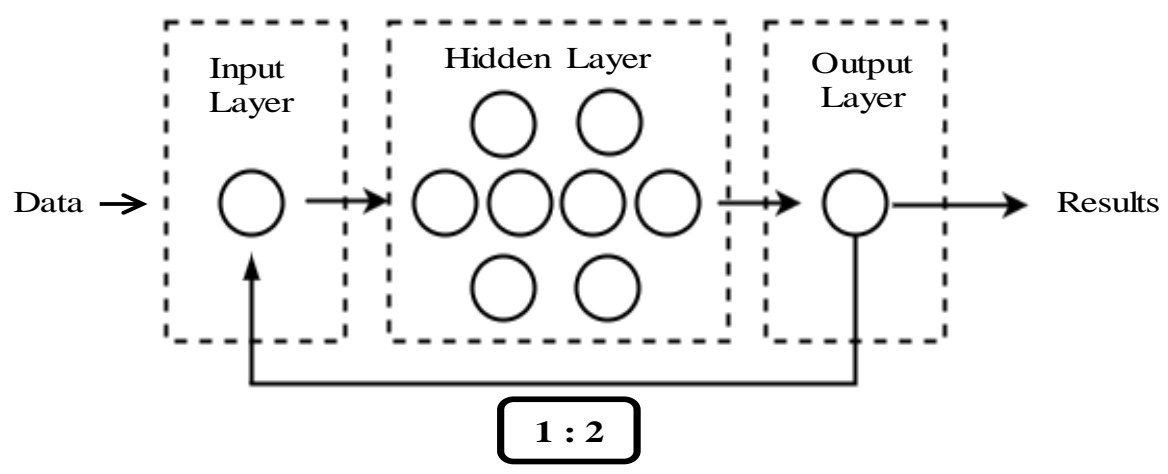

Fig. 9. Closed-loop Dynamic Neural Network

The set of neural networks are trained and the network performance for cylinder no. 8 are demonstrated by presenting the regression plots of the correlation coefficient $R$ for the training and testing data set as shown in Figure 10 and the error autocorrelation as shown in Figure 11. For the other set of networks for the other 7 cylinders, equivalent results were obtained.
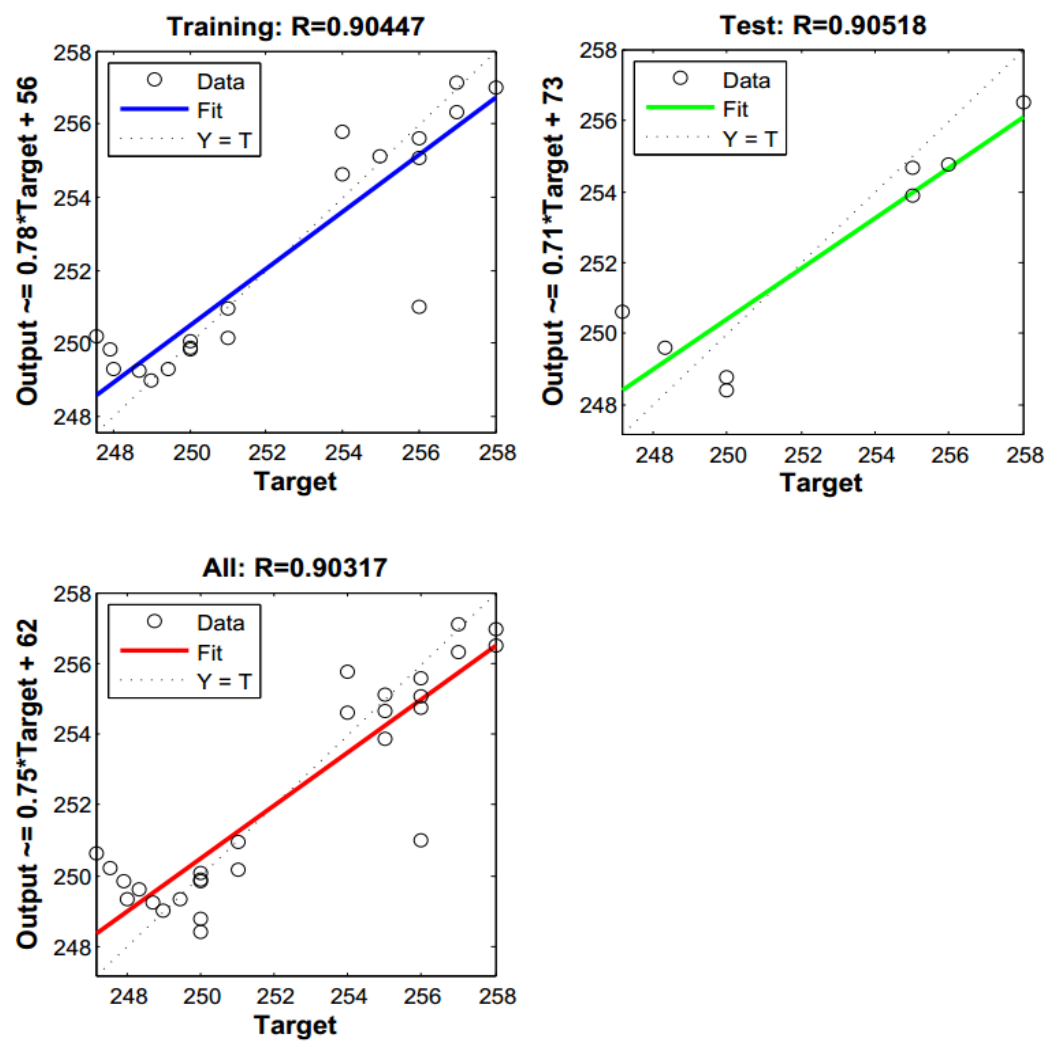

Fig. 10.

Sample regression results for training and test data of neural network

(Cylinder no.8)

The regression plot showing the correlation coefficient $R$ in Figure 10, is a good measure of how well the network has fitted the data. The regression plot shows the actual network outputs plotted in terms of the associated target values. Regression values measure the correlation between outputs and targets. A correlation coefficient $R$ value of 1 implies a perfect fit of outputs exactly equal to targets. Figure 10 displays the network outputs with respect to targets 
for training and test sets. $70 \%$ of the data was used for training purposes and the remaining was used for the test data set. Bayesian regularization does not use a validation set but includes this in the training set. The training data indicate a good fit as does the test data results showing values of $R$ equal to $90 \%$ in both sets

Besides the correlation coefficient, the error autocorrelation is used to validate the network performance. The error autocorrelation function defines how the forecast errors are interrelated in time. For a faultless prediction model, there should be one non-zero value that should occur at zero lag implying that the forecast errors are entirely uncorrelated with each other. Thus, if the network has been trained well then besides the centre line which shows the mean squared error, all other lines should fall within the confidence limits as successfully shown in Figure 11.

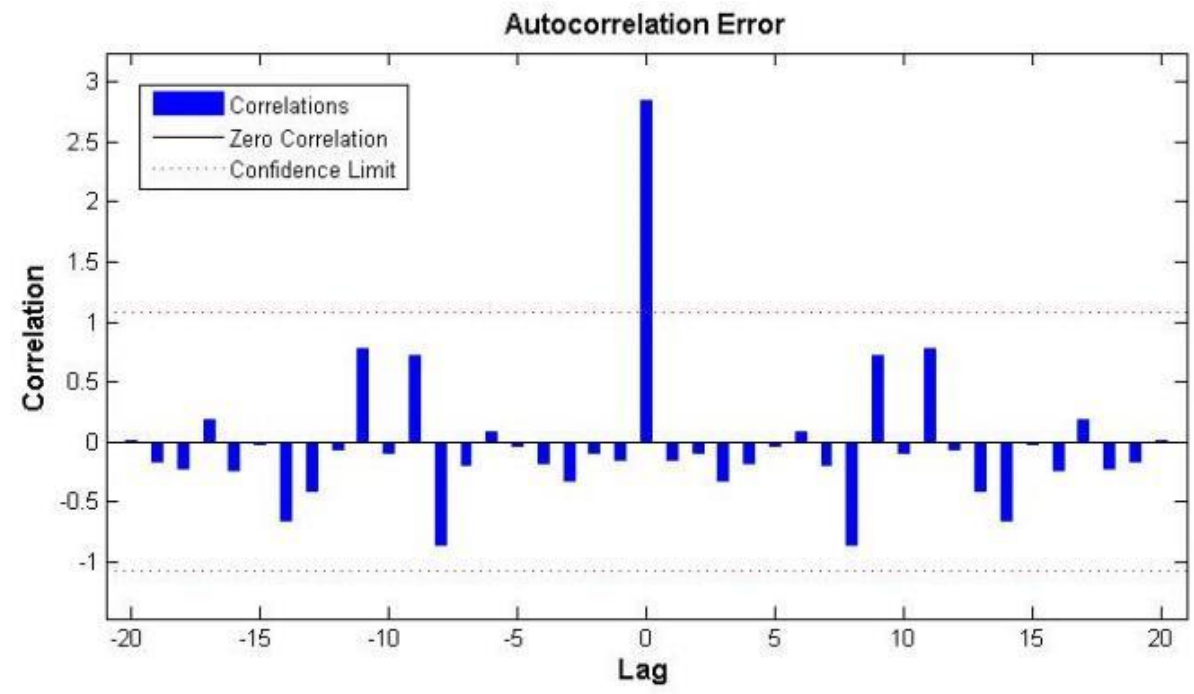

Fig. 11. Sample of autocorrelation of error (cylinder no.8)

The results obtained from the set of neural networks for predicting the future upcoming ten hourly values in time of the cylinder exhaust temperatures are illustrated in Figure 12. 


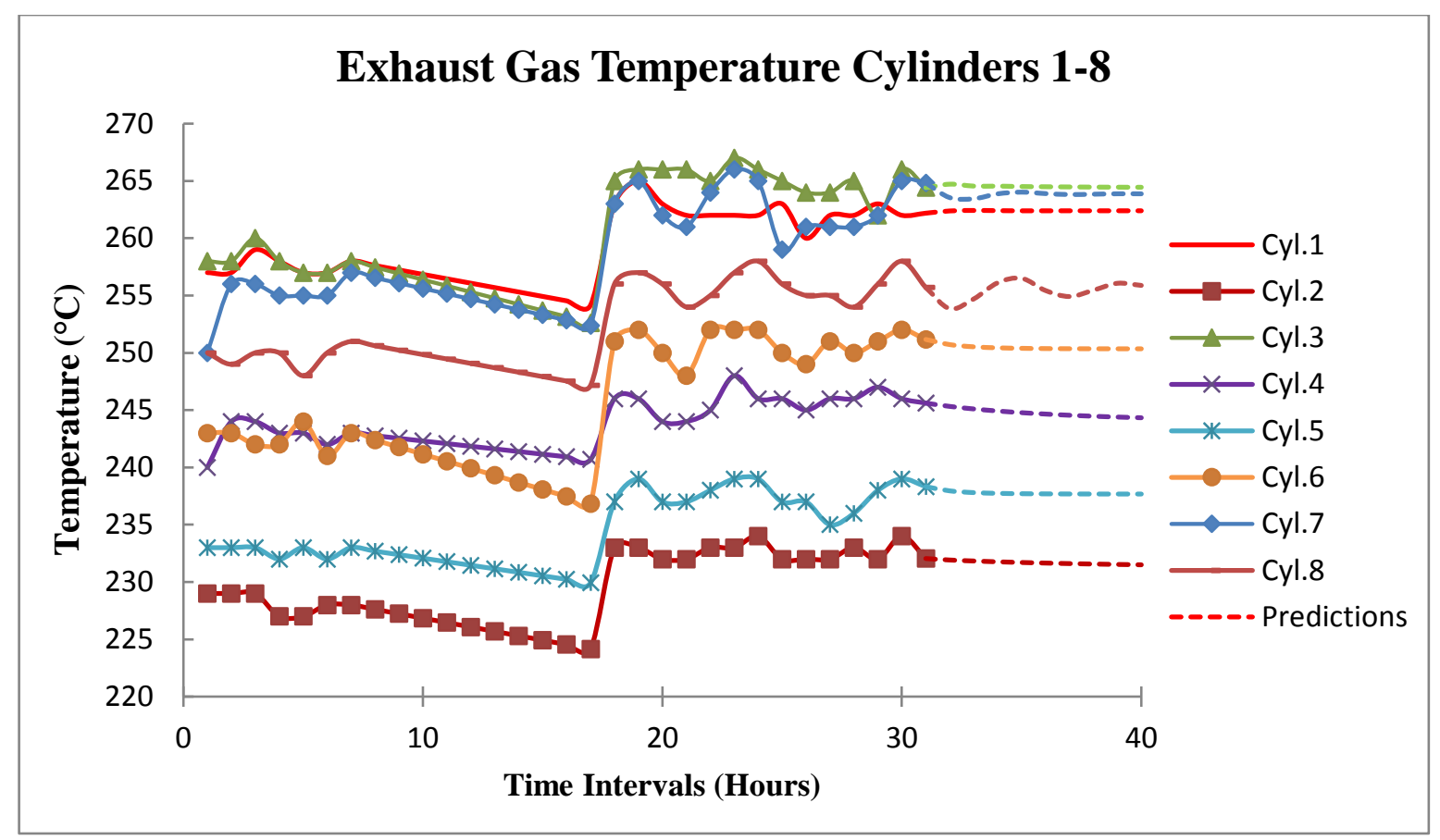

Fig. 12. Cylinders no.1-8 exhaust gas temperature predictions

Figure 12 illustrates the graph of the recorded values and predicted ones against time for the exhaust gas temperatures of every cylinder of the ship main engine. The first 30 hourly measurements are the recorded values from the on board measurement campaign, while the last 10 hourly data points, from 30 hours until 40 hours are the ones forecasted from each neural network.

The recorded temperatures for all cylinders are within the range of 220 degrees to 270 degrees Celsius. Variations in the cylinder temperatures could be the result of the specific state and condition of each individual cylinder. Specifically, an increase of around 10 degrees Celsius for the exhaust gas temperatures for all cylinders after 17-18 hours of operation are observed and are mainly caused by an increase in the engine and fuel load. This is due to the engine governor regulating the engine speed, as the vessel was also sailing at a constant speed of 10 knots during transient operation in the Mediterranean Sea. Moreover, localised weather conditions such as current, waves and wind direction could all be possible factors.

Moreover, the data used represents cylinder exhaust gas temperatures while the vessel was in transient operation. Since no failures occurred during the on board measurement and no significant fluctuations were observed in the vessel's speed and engine's rpm, the obtained data does not cover the whole operational range of the system and further research is required to investigate the capability of the developed neural network to forecast parameters during various engine loads and speeds. However, the neural network developed was capable of accurate time series predictions by using appropriate training algorithms and network structure. Besides the network performance, the first 5 hourly forecasted values from the network are compared in Table 4 with the actual values recorded on board the vessel for validation purposes. 
Table 4 Comparison of on board values with ANN predictions for the Exhaust Gas Temperatures for all cylinders

\begin{tabular}{|c|c|c|c|c|c|c|}
\hline \multirow{3}{*}{$\begin{array}{c}\text { Cylinder } \\
1\end{array}$} & On Board & 262.2 & 262.4 & 262.4 & 262.4 & 262.4 \\
\hline & ANN Prediction & 263.0 & 260.0 & 262.0 & 262.0 & 263.0 \\
\hline & Error & $0.31 \%$ & $0.92 \%$ & $0.16 \%$ & $0.16 \%$ & $0.23 \%$ \\
\hline \multirow{3}{*}{$\begin{array}{c}\text { Cylinder } \\
2\end{array}$} & On Board & 232.1 & 231.9 & 231.8 & 231.8 & 231.7 \\
\hline & ANN Prediction & 232.0 & 232.0 & 232.0 & 233.0 & 232.0 \\
\hline & Error & $0.02 \%$ & $0.03 \%$ & $0.07 \%$ & $0.53 \%$ & $0.13 \%$ \\
\hline \multirow{3}{*}{$\begin{array}{c}\text { Cylinder } \\
3\end{array}$} & On Board & 264.4 & 264.7 & 264.5 & 264.5 & 264.5 \\
\hline & ANN Prediction & 265.0 & 264.0 & 264.0 & 265.0 & 262.0 \\
\hline & Error & $0.22 \%$ & $0.27 \%$ & $0.21 \%$ & $0.17 \%$ & $0.96 \%$ \\
\hline \multirow{3}{*}{$\begin{array}{c}\text { Cylinder } \\
4\end{array}$} & On Board & 245.6 & 245.3 & 245.1 & 244.9 & 244.8 \\
\hline & ANN Prediction & 246.0 & 245.0 & 246.0 & 246.0 & 247.0 \\
\hline & Error & $0.16 \%$ & $0.13 \%$ & $0.36 \%$ & $0.44 \%$ & $0.90 \%$ \\
\hline \multirow{3}{*}{$\begin{array}{c}\text { Cylinder } \\
5\end{array}$} & On Board & 238.3 & 238.0 & 237.8 & 237.7 & 237.7 \\
\hline & ANN Prediction & 237.0 & 237.0 & 235.0 & 236.0 & 238.0 \\
\hline & Error & $0.56 \%$ & $0.40 \%$ & $1.19 \%$ & $0.74 \%$ & $0.12 \%$ \\
\hline \multirow{3}{*}{$\begin{array}{c}\text { Cylinder } \\
6\end{array}$} & On Board & 251.2 & 250.7 & 250.5 & 250.4 & 250.4 \\
\hline & ANN Prediction & 250.0 & 249.0 & 251.0 & 250.0 & 251.0 \\
\hline & Error & $0.47 \%$ & $0.69 \%$ & $0.19 \%$ & $0.17 \%$ & $0.24 \%$ \\
\hline \multirow{3}{*}{$\begin{array}{c}\text { Cylinder } \\
7\end{array}$} & On Board & 264.8 & 263.5 & 263.4 & 263.9 & 264.0 \\
\hline & ANN Prediction & 259.0 & 261.0 & 261.0 & 261.0 & 262.0 \\
\hline & Error & $2.25 \%$ & $0.97 \%$ & $0.94 \%$ & $1.10 \%$ & $0.77 \%$ \\
\hline \multirow{3}{*}{$\begin{array}{c}\text { Cylinder } \\
8\end{array}$} & On Board & 255.7 & 253.9 & 254.7 & 256.1 & 256.5 \\
\hline & ANN Prediction & 256.0 & 255.0 & 255.0 & 254.0 & 256.0 \\
\hline & Error & $0.12 \%$ & $0.45 \%$ & $0.12 \%$ & $0.83 \%$ & $0.20 \%$ \\
\hline
\end{tabular}

As observed from Table 4, the error between the actual and predicted values is under $1 \%$. As such, the performance and accuracy of the trained neural networks are verified, indicating its satisfying predictive time series capabilities.

\section{Discussion \& Conclusions}

The combination of the FTA with the FMEA tool provided a good insight for identifying subsystems and their components affecting the main engine through qualitative analysis using minimal cut sets. A minimal cut set is the smallest set of basic events which result in the occurrence of the top event. FMEA also provided insight into possible failure events and causes and contributed in identifying which physical parameters could be further examined in order to investigate the performance and operation of the systems of interest.

In the case in which physical parameters are not applicable to a specific system by examining both the FTA and FMEA, such as the $5^{\text {th }}$ minimal cut sets in Table 2 referring to the fuel oil filter, then counter-measures and maintenance actions have to be implemented in order to successfully maintain this component or system. Overall, the combination of these tools can contribute to an initial reliability assessment of a complex system. The FTA can assist in identifying critical items that affect the overall performance and reliability of a system. In terms of the FTA, if historical data is available such as failure rates or mean time between failures, 
then quantitative analysis can also be performed in order to examine the criticality of various event contributing to the overall failure or occurrence of the top undesired event.

In an era in which big data and the internet of things is becoming a reality and the shipping industry is endeavouring to advance, there is no clear definition of big data and it is still challenging to quantify the volume of data required for successful machine learning, data training and analysis. Developments in sensor technology progressively permit shipping companies and operators to engage in monitoring activities in a more reliable and cost-effective manner, with a higher Return on Investment (ROI). This will permit future applications of datadriven models in the maritime industry more feasible and possible. However, privacy issues, data protection and privacy-related risks pose challenges for the development of big data methods and tools. Moreover, for effective analysis of collected data, availability of skilled workers and software tools is necessary in addition to the required resources for investigating and developing this type of tools. Non-standardised collection of machinery data also limits the infrastructure and general applicability of such methods in the maritime industry, as incompatible data standards may cause issues. Therefore, suitable uncertainty quantification is crucial in order to derive correct data analysis results and avoid false-positive results.

Neural networks learn from past examples and capture subtle functional relationships among the data even if the underlying relationships are hard to describe or unknown. They do not rely on priori principles or statistics models and can significantly simplify the model synthesized process. Moreover, the ANN methodology described was applied for all 8 cylinders of the main engine by creating a set of parallel networks. Because neural networks are a data-based method, they are universally applicable to systems from different industrial application fields. Modelling an effective and accurate neural network structure is based upon the number of neurons, number of hidden layers, values of the weights and biases, type of the activation function, structure of the network, training algorithms as well as data structure. Usually, the ideal network topology is found through testing different network configurations and choosing the one whose performance criteria are greater. Another closely related issue in ANN model building is related to discovering the best way to split up the data, and how large the training and/or test data sets should be.

In conclusion, the FMEA and FTA tools can complement each other, providing a good general model for obtaining critical systems of interest alongside their possible failure causes and effects and relevant physical parameters, which if monitored can provide useful information regarding the performance of the systems and components of interest. The use of the ANN offers a more specific direction in terms of examining and monitoring the condition of the identified Fault Tree components though the time series analysis of their physical parameters. The set of parallel networks contribute to the development of an overall prediction model which will be utilised within a maintenance and condition monitoring framework in order to assess the performance of ship machinery based on past observations and current information and can be used for prognostic and diagnostic purposes and applications. In order to ensure that the prediction model is trustworthy and reliable, uncertainty and sensitivity analysis methods should also be investigated. Future steps in this direction include the examination of more machinery systems by also including alongside their physical parameters various engine loads. 
Furthermore, the development of alarm levels and thresholds should be developed for the prediction model. The alarms and thresholds can be based on either user defined limits, original equipment manufacturer recommendations or parameter deviations from an established baseline. Finally, training and testing of the neural network with big data sets will assist in investigating the accuracy of the network in its predictive capabilities and selecting the optimum neural network algorithms and configurations.

\section{ACKNOWLEDMENTS}

The work in this paper is partially funded by INCASS project. INCASS has received research funding from the European Union's Seventh Framework Programme under grant agreement No. 605200. This publication reflects only the authors' views and European Union is not liable for any use that may be made of the information contained herein. The authors would like to express their sincere gratitude to Dr Victoria Catterson (University of Strathclyde) for her valuable input.

\section{REFERENCES}

ABS 2015a. Guidance notes on Failure Mode and Effects Analysis (FMEA) for classification. In: ABS (ed.). Houston, TX USA.

ABS 2015b. NS5 Enterprise-Asset Management Solutions. Houston, TX USA.

AIZENBERG, I., SHEREMETOV, L., VILLA-VARGAS, L. \& MARTINEZ-MUÑOZ, J. 2016. Multilayer Neural Network with Multi-Valued Neurons in time series forecasting of oil production. Neurocomputing, 175, Part B, 980-989.

ANANTHARAMAN, M., KHAN, F., GARANIYA, V. \& LEWARN, B. 2014. A Step by Step Approach for Evaluating the Reliability of the Main Engine Lube Oil System for a Ship's Propulsion System. TransNav: International Journal on Marine Navigation and Safety of Sea Transportation, 8, 367--371.

ARUNRAJ, N. S. \& MAITI, J. 2007. Risk-based maintenance-Techniques and applications. Journal of Hazardous Materials, 142, 653-661.

BEN-DAYA, M. \& KNEZEVIC, J. 2009. Handbook of maintenance management and engineering, New York, USA, Springer.

BS 2012. Condition monitoring and diagnostics of machines. BS ISO 13372:2012. London, UK: BSI.

CICEK, K. \& CELIK, M. 2013. Application of failure modes and effects analysis to main engine crankcase explosion failure on-board ship. Safety Science, 51, 6-10.

CLASSNK 2013. PrimeShip-Intergrated System for Ship Performance Capability. Tokyo, Japan.

DEKKER, R. 1996. Applications of maintenance optimization models: a review and analysis. Reliability Engineering \& System Safety, 51, 229-240.

EMOVON, I. 2016. Multi-criteria decision making support tools for maintenance of marine machinery systems. Doctor of Philosophy, Newcastle University.

GAO, S. \& KANG, J. 2016. Group Maintenance Strategy for FPSO Offloading System Based on Reliability Analysis. 35th International Conference on Ocean, Offshore and Arctic Engineering. Busan, Korea.

GUAN, Y., ZHAO, J., SHI, T. \& ZHU, P. 2016. Fault tree analysis of fire and explosion accidents for dual fuel (diesel/natural gas) ship engine rooms. Journal of Marine Science and Application, 15, 331-335. 
GUOPING, L., QINGWEI, Z. \& XIAO, M. 2013. Combination of fault tree and neural networks in excavator diagnosis. Indonesian Journal of Electrical Engineering and Computer Science, 11, 1787-1796.

HAYKIN, S. 1998. Neural Networks: A Comprehensive Foundation, NJ, USA, Prentice Hall PTR.

HIDALGO, E. M. P., SILVA, D. W. R. \& SOUZA, G. FMEA and FTA analysis applied to the steering system of LNG carriers for the selection of maintenance policies. Proceeding of the 21st Brazilian Congress of Mechanical Engineering. Natal, Brazil, 2011.

HIPEL, K. W. \& MCLEOD, A. I. 1994. Time series modelling of water resources and environmental systems, Amsterdam, The Netherlands, Elsevier.

IACS 2014. Recommendation for the FMEA process for diesel engine control systems. IACS Rec. 2014. London, UK.

IMO 1993. International Safety Management (ISM) Code, Resolution A741(18). London, UK.

INCASS 2014a. Deliverable D4.1 Specification of requirements for machinery and equipment. INCASS-Inspection Capabilities for Enhanced Ship Safety. UK: EC FP7 Project.

INCASS 2014b. Deliverable D4.2 Stakeholders' data requirements. INCASS-Inspection Capabilities for Enhanced Ship Safety. UK: EC FP7 Project.

ISERMANN, R. 2006. Fault-diagnosis systems: an introduction from fault detection to fault tolerance, Berlin, Germany, Springer Science \& Business Media.

KAYRI, M. 2016. Predictive Abilities of Bayesian Regularization and Levenberg-Marquardt Algorithms in Artificial Neural Networks: A Comparative Empirical Study on Social Data. Mathematical and Computational Applications, 21, 20.

KNUTSEN, K. E., MANNO, G. \& VARTDAL, B. J. 2014. Beyond Condition Monitoring in the Maritime Industry. Norway: DNV-GL.

LABOISSIERE, L. A., FERNANDES, R. A. S. \& LAGE, G. G. 2015. Maximum and minimum stock price forecasting of Brazilian power distribution companies based on artificial neural networks. Applied Soft Computing, 35, 66-74.

LASKOWSKI, R. 2015. Fault Tree Analysis as a tool for modelling the marine main engine reliability structure. Scientific Journals of the Maritime University of Szczecin, 71--77.

LAZAKIS, I. \& ÖLÇER, A. 2015. Selection of the best maintenance approach in the maritime industry under fuzzy multiple attributive group decision-making environment. Proceedings of the Institution of Mechanical Engineers, Part M: Journal of Engineering for the Maritime Environment, 1-13.

LAZAKIS, I., TURAN, O. \& AKSU, S. 2010. Increasing ship operational reliability through the implementation of a holistic maintenance management strategy. Ships and Offshore Structures, 5, 337-357.

LIU, H., TIAN, H.-Q., LIANG, X.-F. \& LI, Y.-F. 2015. Wind speed forecasting approach using secondary decomposition algorithm and Elman neural networks. Applied Energy, 157, 183-194.

LLOYDS REGISTER 2013. Machinery Planned Maintenance \& Condition Monitoring. London, UK.

MANZINI, R., REGATTIERI, A., PHAM, H. \& FERRARI, E. 2009. Maintenance for industrial systems, London, UK, Springer Science \& Business Media.

MOKASHI, A. J., WANG, J. \& VERMAR, A. K. 2002. A study of reliability-centred maintenance in maritime operations. Marine Policy, 26, 325-335.

NASA 2002. Fault Tree Handbook with Aerospace Applications. In: STAMATELATOS, M. \& VESELY, W. (eds.). Washington, DC. 
NASR, M. S., MOUSTAFA, M. A. E., SEIF, H. A. E. \& EL KOBROSY, G. 2012. Application of Artificial Neural Network (ANN) for the prediction of EL-AGAMY wastewater treatment plant performance-EGYPT. Alexandria Engineering Journal, $51,37-43$.

NOOR, M., MH, M. Y. \& MM, N. 2016. Prediction of Marine Diesel Engine Performance by Using Artificial Neural Network Model. Journal of Mechanical Engineering and Sciences (JMES), 10, 1917-1930.

NUREG-0492 1981. Fault Tree Handbook U.S. Nuclear Regulatory Commission. Washington, DC.

OLADOKIN, V. O., CHARLES-OWABA, O. E. \& NWAOUZRU, C. S. 2006. An application of artificial neural network to maintenance management. Journal of Industrial Engineering International, 2, 19-26.

PASCUAL, D. G. 2015. Artificial Intelligence Tools: Decision Support Systems in Condition Monitoring and Diagnosis, USA, Crc Press.

PENG, Y., DONG, M. \& ZUO, M. J. 2010. Current status of machine prognostics in condition-based maintenance: a review. The International Journal of Advanced Manufacturing Technology, 50, 297-313.

PINTELON, L. \& PARODI-HERZ, A. 2008. Maintenance: An Evolutionary Perspective. Complex System Maintenance Handbook. London, UK: Springer

RAPTODIMOS, Y. \& LAZAKIS, I. 2016. An artificial neural network approach for predicting the performance of ship machinery equipment. Maritime Safety and Operations 2016 Conference Proceedings.

RAPTODIMOS, Y., LAZAKIS, I., THEOTOKATOS, G., VARELAS, T. \& DRIKOS, L. Ship sensors data collection and analysis for condition monitoring of ship structures and machinery systems. Smart Ships 2016 Conference, 2016/1/27 2016 London. Royal Institution of Naval Architects.

RAUSAND, M. \& ARNLJOT, H. 2004. System reliability theory: models, statistical methods, and applications, John Wiley \& Sons.

RAZA, J. \& LIYANAGE, J. P. 2009. Application of intelligent technique to identify hidden abnormalities in a system: A case study from oil export pumps from an offshore oil production facility. Journal of Quality in Maintenance Engineering, 15, 221-235.

RELEX 2009. Relex Reliability Studio Reference Manual. USA: Relex Software Corporation.

RUILIN, Z. \& LOWNDES, I. S. 2010. The application of a coupled artificial neural network and fault tree analysis model to predict coal and gas outbursts. International Journal of Coal Geology, 84, 141-152.

SOUZA, R. \& ÁLVARES, A. J. FMEA and FTA analysis for application of the reliabilitycentered maintenance methodology: case study on hydraulic turbines. AVCM Symposium Series in Mechatronics, 2008. 803-812.

STOPFORD, M. 2009. Maritime economics $3 e$, New York, USA, Routledge.

SZOPLIK, J. 2015. Forecasting of natural gas consumption with artificial neural networks. Energy, 85, 208-220.

TINSLEY, D. 2016. Dawning of new era in asset maintenance. Marine Power \& Propulsion Supplement 2016. London: The Royal Institution of Naval Architects.

TURAN, O., LAZAKIS, I., JUDAH, S. \& INCECIK, A. 2011. Investigating the reliability and criticality of the maintenance characteristics of a diving support vessel. Quality and Reliability Engineering International, 27, 931-946.

VERMA, A. K., SRIVIDYA, A. \& KARANKI, D. R. 2010. Reliability and safety engineering, London, UK, Springer. 
ZHANG, G., EDDY PATUWO, B. \& Y. HU, M. 1998. Forecasting with artificial neural networks: The state of the art. International Journal of Forecasting, 14, 35-62.

ZHANG, G. P., PATUWO, B. E. \& HU, M. Y. 2001. A simulation study of artificial neural networks for nonlinear time-series forecasting. Comput. Oper. Res., 28, 381-396. 